\title{
DNA Isolation from soil samples for cloning in different hosts
}

Isabelle M. Kauffmann, Jutta Schmitt and Rolf D. Schmid ${ }^{1}$

Institut für technische Biochemie, Universität Stuttgart, Allmandring 31, 70569 Stuttgart

${ }^{1}$ corresponding author

Prof. R. D. Schmid

Institut für technische Biochemie

Universität Stuttgart

Allmandring 31

D-70569 Stuttgart

Germany

Phone: +49-711-685-3192

Fax: $\quad+49-711-685-3196$

E-mail: $\quad \underline{\text { itbrsc@po.uni-stuttgart }}$ 


\begin{abstract}
Many protocols to extract DNA directly from soil samples have been developed in recent years. We employed two extraction methods which differed in the method of lysis and compared these methods with respect to yield, purity and degree of shearing. The main focus was on the specific isolation of DNA from different microorganisms, especially DNA from actinomycetes, as these cells are very difficult to lyse in contrast to non-actinomycetes. Thus, we used both methods to isolate DNA from Pseudomonas (Entcheva et al. 2001), Arthrobacter and Rhodococcus (Borneman et al. 1996) and from soil spiked with the respective microorganisms. Both methods rendered high DNA yields with a low degree of shearing but differed in the type of cells that were lysed. By one protocol (utilizing enzymatic lysis) only DNA from the Gram-negative Pseudomonas strain could be obtained whereas by the other protocol (utilizing mechanical lysis), all microorganisms that were used could be lysed and DNA from them extracted. Using a combination of both protocols, DNA from those organisms could be obtained selectively. Furthermore, one of the protocols was modified, resulting in higher DNA yield and purity.
\end{abstract}




\section{Introduction}

Microorganisms offer a huge potential for new biocatalysts for industrial and commercial applications. The classical approach to gain access to new biocatalysts is to cultivate microorganisms from soil samples in different media and screen for the desired enzyme activity. However only a very small proportion of the total microbial community of a soil sample can be isolated by cell cultivation in standard media (Torsvik et al. 1990) (Jacobsen and Rasmussen 1992), current estimates indicate that approximately $99 \%$ of microorganisms occuring in nature cannot be cultivated by standard techniques (Amann et al. 1995). An alternative method is to isolate DNA directly from the microorganisms present in the soil without prior culturing. This DNA can be used for the construction of DNA libraries and to directly clone functional genes from environmental samples. Many protocols for isolating DNA from environmental samples have been developed, which vary with respect to the degree of shearing, purity and quantity of the isolated DNA. DNA may be extracted from soil samples directly (Tebbe and Vahjen 1993) (Selenska and Klingmuller 1991) (Wikstrom et al. 1996) or the microorganisms of the soil sample can be first extracted and lysed subsequently (Steffan et al. 1988). Direct extraction of DNA introduces less bias than methods which are based on cell extraction prior to lysis (von Wintzingerode et al. 1997). To extract DNA, the microorganisms in the soil can be lysed mechanically by bead-beating (Moré et al. 1994) (Berthelet et al. 1996) (Purdy et al. 1996), sonication (Degrange and Bardin 1995), freezethawing (Lee et al. 1996), grinding in liquid nitrogen (Johnston and Aust 1994) (Volossiouk et al. 1995) or enzymatically, using enzymes such as proteinase K (Wikstrom et al. 1996; Zhou et al. 1996), lysozyme (Porteous et al. 1994) or pronase. A combination of these treatments may also be applied (Tsai and Olson 1991) (Tebbe and Vahjen 1993) (Picard et al. 1992). In addition SDS or other detergents are frequently added. 
The construction of environmental DNA libraries presents special problems. E. coli doesn't recognize approximately $80 \%$ of actinomycete promoters (Strohl 1992) and the G $+\mathrm{C}$ content of the DNA to be cloned and expressed may differ significantly. Hence, a great number of genes present in the sample are unlikely to be adequately expressed in E. coli. However, if a library is to be screened for enzymatic activities, the number of functionally expressed genes should be as high as possible, i. e. DNA from organisms that can barely be expressed should be excluded in the respective host. Thus it is desirable to exclude actinomycete genes when E. coli is used as host. On the other hand, actinomycetes possess interesting enzymatic activities, the genes for which are rarely expressed in E. coli. Therefore, this DNA could be expressed in an alternative host to E. coli for example Streptomyces.

Two methods for the extraction of DNA were compared with regard to DNA yield, shearing of DNA and purity using Gram-positive and Gram-negative microorganisms. Moreover it was investigated whether DNA from all applied strains could be extracted in similar amounts or if a bias of DNA originating from different species can be obtained by the choice of the DNA extraction method. 


\section{Materials and methods}

Bacterial strains: The bacterial strains used were Pseudomonas LU2023, Arthrobacter LU9144 and Rhodococcus LU 9002 (all BASF AG, Ludwigshafen). All strains were grown to the stationary phase in LB-medium at $30^{\circ} \mathrm{C}$.

Escherichia coli DH5 $\alpha$ and Streptomyces antibioticus TÜ4 were used as controls for Gram negative and Gram positive organisms in the PCR reactions.

\section{Soil DNA extraction and purification:}

Zhou-method, (Zhou et al. 1996) modified : Soil samples $(0.5 \mathrm{~g})$ were mixed with $1.3 \mathrm{ml}$ of extraction buffer (100 mM Tris-HCl [pH8.0], $100 \mathrm{mM}$ sodium-EDTA [pH 8.0], $100 \mathrm{mM}$ sodium-phosphate [pH 8.0], 1,5 M NaCl, 1\% (w/v) hexadecylmethylammonium bromide $(\mathrm{CTAB}))$ in $15 \mathrm{ml}$ Falcon tubes. Three cycles of freezing in liquid nitrogen and thawing in a water bath at $65^{\circ} \mathrm{C}$ were then applied to the suspensions. After the samples had cooled down to $37^{\circ} \mathrm{C} 10 \mu \mathrm{l}$ of proteinase $\mathrm{K}(20 \mathrm{mg} / \mathrm{ml})$ was added and the samples were incubated at $37^{\circ} \mathrm{C}$ for 30 min with horizontal shaking. $150 \mu 1$ of $20 \%(w / v)$ SDS was then added and the samples were incubated in a water bath at $65^{\circ} \mathrm{C}$ for $2 \mathrm{~h}$. After centrifugation at $3200 \mathrm{xg}$ for $10 \mathrm{~min}$ at $4^{\circ} \mathrm{C}$ the supernatants were transferred to $15 \mathrm{ml}$ Falcon-tubes. The soil pellets were washed by adding $1 \mathrm{ml}$ extraction buffer and $250 \mu 120 \%$ SDS, vortexed, incubated for 10 $\min$ at $65^{\circ} \mathrm{C}$ and centrifuged as before. The aqueous phases were extracted with chloroform and precipitated with 0.7 volumes isopropanol at $-20^{\circ} \mathrm{C}$ for $1 \mathrm{~h}$. After centrifugation at 20 $800 \mathrm{x}$ g for $25 \mathrm{~min}$ at $4^{\circ} \mathrm{C}$ the pellets were washed with ice cold $70 \%$ ethanol, recentrifuged, dried and resuspended in $100 \mu \mathrm{TE}$ buffer (10 mM Tris, 1 mM EDTA, pH 8).

For PCR application the DNA was either purified 3 times with the Wizard DNA clean-up System (Promega, Madison) or purified once with the Wizard DNA clean-up System and subsequently by agarose gel electrophoresis. After gel electrophoresis, DNA was eluted with 
the Gel-extraction Kit (Biozym, Hess. Oldendorf) according to the manufacturer's instructions.

Moré-method, (Moré et al. 1994) modified: 0.5 g soil samples were mixed with $500 \mu 1100$ $\mathrm{mM}$ sodium phosphate buffer ( $\mathrm{pH} 8.0)$ in $2 \mathrm{ml}$ Eppendorf tubes. Then $2 \mathrm{~g}$ of glass beads $(0.1$ $\mathrm{mm}-0.25 \mathrm{~mm}$ diameter) and $250 \mu \mathrm{l}$ of a $10 \%$ SDS solution $(100 \mathrm{mM} \mathrm{NaCl}, 500 \mathrm{mM}$ Tris $(\mathrm{pH} 8.0), 10 \%(\mathrm{w} / \mathrm{v})$ SDS) were added. Each tube was shaken at an amplitude of $8000 \mathrm{~min}^{-1}$ for $10 \mathrm{~min}$ in a bead-mill (Retsch, Haan) before being centrifuged at $20800 \times \mathrm{g}$ for $3 \mathrm{~min}$ at room temperature. The supernatant was kept on ice, the soil pellet was washed with $250 \mu 1$ sodium phosphate buffer, mixed and treated for $2 \mathrm{~min}$ in an ultrasonic bath. After centrifugation the supernatants were pooled, mixed 5:2 with 7.5 M ammonium acetate, precipitated for $5 \mathrm{~min}$ on ice and centrifuged at $20800 \mathrm{x}$ g for $3 \mathrm{~min}$.

The supernatant was precipitated with 2.5 volumes ethanol according to standard protocols (Sambrook et al. 1989). For PCR applications the DNA obtained by ethanol precipitation was purified 3 times with the Wizard DNA clean-up System (Promega, Madison).

Silica-based purification of DNA, (Höss and Pääbo 1993) modified: The supernatant of the ammonium acetate precipitation obtained by the method of Moré can alternatively be purified directly. Accordingly, 2 volumes extraction buffer ( $5 \mathrm{M}$ guanidine thiocyanate, 50 mM Tris (pH 8.0), $25 \mathrm{mM} \mathrm{NaCl}, 20 \mathrm{mM}$ EDTA, 1.3\% Triton X-100) and 1/10 volumes silica were added to the supernatant. After vortexing, the tubes were centrifuged at $1000 \mathrm{x} g$ for 3 min and the supernatant was discarded. 2 volumes of wash buffer ( $5 \mathrm{M}$ guanidine thiocyanate, $0.1 \mathrm{M}$ Tris ( $\mathrm{pH} 8.0), 25 \mathrm{mM} \mathrm{NaCl}$ ) was added, the silica was resuspended by gentle vortexing and the tube was centrifuged at $1000 \mathrm{x}$ g for $3 \mathrm{~min}$. The supernatant was again discarded and the pellet was washed with $1.5 \mathrm{ml} \mathrm{70 \%} \mathrm{ethanol} \mathrm{and} \mathrm{dried.} \mathrm{The} \mathrm{DNA} \mathrm{was}$ 
eluted by addition of $100 \mu \mathrm{TE}$-buffer, incubation at $55^{\circ} \mathrm{C}$ for $10 \mathrm{~min}$ and centrifugation at $20800 \mathrm{x}$ g for $1 \mathrm{~min}$. The DNA-containing supernatant was transferred to a fresh tube.

PCR-amplification of the 23SrDNA-fragment: An insertion of 100 bases within the domain III of the 23SrRNA is a phylogenetic marker for Gram-positive bacteria with a high GC-content (actinomycetes) whereas other eubacteria don't contain this insertion. To verify the type of DNA isolated, domain III of the 23S-rDNA was amplified by PCR using a mixture of PCR-buffer [10 mM Tris-HCl, pH 8.8; 50 mM KCl, 0.08\% Nonidet P40; 2 mM $\mathrm{MgCl}_{2}$ ] (MBI Fermentas, St. Leon-Rot), $2.5 \mathrm{mM}$ of each deoxynucleotide triphosphate, 50 pmol of each primer (5'CCTAAGYYGAGGC (1900 V), 5'CCTTCTCCCGAAGTTACGG $(1028 \mathrm{R})), 1 \mu \mathrm{l}$ of template DNA and $1 \mathrm{U}$ of Taq Polymerase. After denaturation at $94^{\circ} \mathrm{C}$ for 4 min 30 cycles were performed as follows: $30 \mathrm{sec}$. denaturation at $94^{\circ} \mathrm{C}, 1.30 \mathrm{~min}$ annealing at $46^{\circ} \mathrm{C}$ and $2 \mathrm{~min}$ extension at $72^{\circ} \mathrm{C}$. After a final extension at $72^{\circ} \mathrm{C}$ for $5 \mathrm{~min}$ the samples were cooled down to $8^{\circ} \mathrm{C}$. Then $10 \mu$ of each mixture were separated by agarose gel electrophoresis (Sambrook et al. 1989) in a 2\% agarose gel. Genomic DNA from E. coli and Streptomyces purified by the Qiagen genomic-tip 100 Kit (Qiagen, Hilden) were used as control templates. 


\section{Results}

\section{Comparison of lysis methods}

DNA was isolated from a mixture of different strains (Pseudomonas, Arthrobacter and Rhodococcus ) and from autoclaved soil spiked with the same mixtures and analysed by gel electrophoresis. Two different lysis methods were compared using pure cultures from Pseudomonas, Arthrobacter and Rhodococcus ( Fig. 1A, B) The method according to Zhou is based on cell lysis by freeze-thaw cycles and treatment with proteinase $\mathrm{K}$ and hot SDS in the presence of high salt concentrations. By the method according to Moré cells are lysed by SDS and mechanical disruption by glass beads. These two methods were chosen as they both gave high DNA yields (data not shown) and significantly differ in their mode of action. By the method according to Moré DNA can be isolated from pure cultures of all strains tested (Fig. 1A, lanes $5-7$ ). To study interactions between DNA and soil particles or the influence of soil particles on lysis efficiency, $0.5 \mathrm{~g}$ of autoclaved soil was added per $0.5 \mathrm{ml}$ of pure culture (Fig. 1B). Following the addition of soil the amount of isolated DNA from Pseudomonas was as high as from the pure culture (Fig. 1A, B, lanes 5) but the lysis efficiency towards actinomycetes was strongly reduced when autoclaved soil was added (Fig. 1B, lanes 6 and 7). The method modified according to Zhou was very efficient for Pseudomonas, high DNA yields were obtained and shearing of DNA was low (Fig. 1A, B, lanes 2). In contrast, the lysis efficiency of Rhodococcus and Arthrobacter was very low, both with and without the addition of soil (Fig. 1A, B, lanes 3 - 4).

To confirm, that no DNA can be extracted from autoclaved soil, both DNA extraction methods were performed with autoclaved soil. Fig. 1C shows that no DNA can be extracted from autoclaved soil without the addition of pure cultures, using either extraction method. 
To check the amount of DNA that can be extracted directly from soil samples, DNA isolation methods according to Zhou and Moré were applied to soil samples.

The yield obtained by the method of Moré was comparable to the yield obtained by the method of Zhou, but the DNA was more fragmented when the method of Moré was applied.

\section{Optimization of methods}

DNA isolated by both methods was contaminated with humic compounds that interfere with PCR analysis and other reactions. Additionally the last DNA precipitation step is relatively time consuming. Therefore, it was investigated for both methods whether the DNA could be purified directly without prior precipitation. Accordingly, a direct silica-purification protocol (Höss and Pääbo 1993) was modified and performed instead of isopropanol / ethanol precipitation. After cell disruption and ammonium acetate precipitation of proteins using the Moré method, the supernatant could be treated directly with silica to obtain purer DNA with a yield comparable to that obtained by ethanol precipitation. The same purification procedure was performed with the aqueous phase from the Zhou-protocol after chloroform extraction. In this case the DNA yield was very low in comparison to the isopropanol precipitation (data not shown).

\section{Combination of methods}

For the separation of Pseudomonas DNA from Rhodococcus and Arthrobacter DNA the methods of Zhou and Moré were combined. To $0.5 \mathrm{~g}$ of autoclaved soil i) $1.8 \mathrm{ml}$ Pseudomonas, ii) $900 \mu 1$ each Arthrobacter and Rhodococcus and iii) $600 \mu 1$ each Pseudomonas, Arthrobacter and Rhodococcus, all cultures grown to the stationary phase, were added. All samples were first lysed according to Zhou (Fig. 2, lanes 2-4). 
Subsequently, the remaining intact cells from the soil pellet were disrupted by the method of Moré (Fig. 2, lanes 5-7). Using freeze-thaw cycles, proteinase K and SDS treatment (i. e. the Zhou method) only Pseudomonas can easily be lysed (Fig 2, lane 2) In Fig. 2, lane 4 the amount of extracted DNA is lower than in Fig. 2 lane 2 as the amount of Pseudomonas cells in that sample was 3-fold lower. Lysis of the cells by the method of Moré resulted in the disruption of Pseudomonas as well as Rhodococcus and Arthrobacter cells (Fig. 2, lanes 5 7).

Lysis of the different cell types was confirmed by PCR analysis of 23S-rDNA using specific primers. In the case of $\mathrm{G}+\mathrm{C}$-rich Gram-positive bacteria a fragment of $350 \mathrm{bp}$ was expected in contrast to a $250 \mathrm{bp}$ fragment in the case of other eubacteria. In Fig. 3, lane 2, only one band with a size of $250 \mathrm{bp}$ is visible when the template used for PCR is DNA isolated according to the method of Zhou from a mixture of all 3 strains in autoclaved soil. A band of the same size appeared, when genomic DNA from E. coli served as a template (Fig. 3, lane 5). If the remaining intact cells in the sample are subsequently lysed by the method of Moré and the extracted DNA is amplified by PCR using the same 23S-rDNA-primers, the main product has a size of $350 \mathrm{bp}$ (Fig. 3, lane 3). This product is the same size as the PCR product that was amplified when Streptomyces-DNA was used as template (Fig. 3, lane 4), confirming the presence of the $100 \mathrm{bp}$ insertion. As this insertion is specific to Gram-positive bacteria with a high $\mathrm{G}+\mathrm{C}$ content it proved the lysis of Arthrobacter and Rhodococcus cells.

To check if the fractionated isolation of DNA from real samples is possible the two DNA extraction methods were performed in combination. First the DNA isolation method according to Zhou was applied, then DNA was isolated from the remaining soil pellet by the method of Moré. The isolated DNA from both methods was used as template for PCR amplification of 23S rDNA. PCR products from both templates did not show any band of 350 
bp (data not shown). As this result could be due to a bias of non-actinomycetes in the sample, $200 \mu \mathrm{l}$ of Rhodococcus cells were added to the soil sample and DNA extraction methods were performed as before. PCR analysis of $23 \mathrm{~S}$ rDNA as described above showed that it was not possible to obtain a fragment of $350 \mathrm{bp}$ when using DNA isolated by the method of Zhou as template (Fig. 4, lane 2). However, when DNA isolated subsequently by the method according to Moré served as template both a 250-bp fragment and a $350 \mathrm{bp}$ fragment were visible on the agarose gel (Fig. 4, lane 3), indicating that DNA from Rhodococcus cells was extracted. 


\section{Discussion}

In this study, two different methods for the isolation of DNA from pure cultures, soil samples and soil samples spiked with pure cultures were compared with respect to purity, yield, efficiency and selectivity of DNA extraction from different species.

\section{Comparison of different DNA-extraction methods}

The comparison of the two different lysis methods concerning yield showed that the method according to Moré can be efficiently used to lyse Pseudomonas cells as well Rhodococcus and Arthrobacter cells. The method of Zhou obtains the best results for Pseudomonas, as the yield is very high and the DNA is less fragmented than after isolation according to Moré. However, the DNA isolated by this method is more contaminated with humic compounds than the DNA obtained by application of the method of Moré for cell lysis. This contamination is visible in the brownish pellet. Furthermore, DNA from Rhodococcus and Arthrobacter can hardly be isolated by use of the method according to Zhou, whereas the method according to Moré is effective towards these strains. However, when soil is added to the pure cultures the lysis-efficiency towards Rhodococcus and Arthrobacter is strongly reduced, even with the Moré-method. Presumably the soil particles reduce the effectiveness of the glass beads and therefore DNA can only be efficiently extracted from cells that are easier to disrupt than Rhodococcus and Arthrobacter cells. The method of Zhou introduces a bias towards Gram-negative bacteria, whereas this bias is lower with the method according to Moré. Recent publications (La Montagne et al. 2002) comparing the methods according to Zhou and Porteous (Porteous et al. 1994) show a lower DNA yield is obtained by the method of Porteous (ultrasonic, lysozyme) than with the method of Zhou, but the lower yield does not introduce a bias towards lower community diversity. However, the two methods that were compared here differ strongly in the kind of extraction procedure (freeze-thaw-cycles, 
enzymatically vs. bead beating), whereas the methods compared by La Montagne (La Montagne et al. 2002) are rather similar. Furthermore, another comparison of different DNA extraction methods (Martin-Laurent et al. 2001) clearly shows, that the soil DNA extraction method used can affect both phylotype abundance and composition of the indigenous bacterial community. In that work DNA extraction methods based on mechanical treatment by bead beating were compared. Thus it may be possible that by alteration of the composition of glass beads with the method according to Moré the bias could further be lowered and DNA from a greater number of microorganisms could be obtained.

\section{Modification of the Moré method}

A further problem, that is faced when DNA is isolated directly from soil is its contamination with humic compounds inhibiting for example PCR-reactions (Tsai and Olson 1992). As the DNA isolated by both methods was not pure enough for PCR reactions and restriction digestion, ethanol precipitation was replaced by a direct purification step using silica and guanidine thiocyanate. This procedure resulted in the same DNA yield compared to the ethanol precipitation with the method of Moré. The purity of the isolated DNA, however, was much higher when it was purified with silica. The DNA obtained by ethanol precipitation had to be purified up to 3 times with the Wizard DNA clean-up System (Promega) to be suitable for PCR analysis whereas the silica purified DNA could be used without further treatment for PCR (data not shown).

\section{Combination of methods}

As DNA from Pseudomonas was most effectively extracted using the method of Zhou and the method of Moré also facilitated the extraction of DNA from Arthrobacter and Rhodococcus the two methods for DNA isolation were combined to isolate DNA from a 
mixture of Pseudomonas, Arthrobacter, Rhodococcus and autoclaved soil. The selective isolation of DNA from Gram positive and Gram negative cells was confirmed by PCRanalysis using 23S-rDNA-specific primers. Applying the method of Zhou to a mixture of all three strains and autoclaved soil lead exclusively to the recovery of DNA from Pseudomonas, as demonstrated by the main PCR product being $250 \mathrm{bp}$ in size. DNA from actinomycetes possesses a $100 \mathrm{bp}$-insertion at this site in the $23 \mathrm{~S}$ rDNA resulting in a PCR product of 350 bp (Roller et al. 1992). After further lysis of remaining cells by the method of Moré and subsequent PCR analysis using the same primers the main PCR-product contains the actinomycete-characteristic $100 \mathrm{bp}$-insertion. Thus, we were able to show that by the combination of freeze-thaw-cycles, SDS and proteinase K Pseudomonas cells can be lysed and DNA extracted, whereas DNA from Arthrobacter and Rhodococcus cannot be obtained by this process, probably due to inefficient cell lysis. By further treatment of the samples using glass beads the remaining Arthrobacter and Rhodococcus cells in the sample were disrupted. The combination of both methods is therefore suitable to selectively isolate DNA from different microorganisms.

To test if this selective cell lysis by combination of the two methods can also be obtained with environmental samples, DNA was isolated from 0,5 g soil samples. Initial PCR analysis of $23 \mathrm{~S}$ rDNA did not result in a $350 \mathrm{bp}$ fragment from templates isolated by neither methods. This could be due to a strong bias of non actinomycetes in the soil sample. To test this the sample was spiked with $200 \mu 1$ Rhodococcus cells. PCR analysis with 23S rDNA specific primers resulted in a $250 \mathrm{bp}$-fragment using the DNA extracted from soil by the method of Zhou as template. When DNA that was isolated subsequently by the More method from the remaining microorganisms in the sample was used for PCR analysis, both a $250 \mathrm{bp}$ fragment and a $350 \mathrm{bp}$ fragment were visible after agarose gel electrophoresis. This shows that it is possible to avoid isolation of actinomycete DNA from soil samples by using the method of 
Zhou. Applying the method according to Moré subsequently allows isolation of actinomycete DNA as well as DNA from other gram positive and gram negative bacteria that could escape lysis by the method of Zhou.

\section{Conclusions:}

E. coli expresses actinomycete genes very inefficiently as only $20 \%$ of actinomycetepromoters can be recognized by E. coli (Strohl 1992) and because of the high G + C-content of actinomycete genes. For the construction of libraries the DNA isolated by the method of Zhou is suitable for cloning in E. coli as host because DNA from actinomycetes can hardly be extracted. This reduces the number of colonies carrying genes from actinomycetes that cannot be expressed in E. coli and therefore reduces the number of clones identified as negative. On the other hand if a library is to be constructed in Streptomyces it is useful to take DNA from a combination of both methods (Zhou and Moré). This reduces the amount of DNA obtained from gram negative organisms and allows the extraction of DNA from actinomycetes that are hard to lyse.

\section{Acknowledgements:}

This work was supported by the BASF AG, Ludwigshafen and the BMBF (Bundesministerium für Bildung und Forschung). We thank Ms Marian Turner for critically reading the manuscript. 


\section{References}

Amann, RI, Ludwig, W and Schleifer, KH (1995). "Phylogenetic identification and in situ detection of individual microbial cells without cultivation." Microbiol Rev 59(1): 14369.

Berthelet, M, Whyte, LG and Greer, CW (1996). "Rapid, direct extraction of DNA from soils for PCR analysis using polyvinylpolypyrrolidone spin columns." FEMS Microbiol Lett 138(1): 17-22.

Borneman, J, Skroch, PW, O'Sullivan, KM, Palus, JA, Rumjanek, NG, Jansen, JL, Nienhuis, $\mathrm{J}$ and Triplett, EW (1996). "Molecular microbial diversity of an agricultural soil in Wisconsin." Appl Environ Microbiol 62(6): 1935-43.

Degrange, V and Bardin, R (1995). "Detection and counting of Nitrobacter populations in soil by PCR." Appl Environ Microbiol 61(6): 2093-8.

Entcheva, P, Liebl, W, Johann, A, Hartsch, T and Streit, WR (2001). "Direct cloning from enrichment cultures, a reliable strategy for isolation of complete operons and genes from microbial consortia." Appl Environ Microbiol 67(1): 89-99.

Höss, M and Pääbo, S (1993). "DNA extraction from pleistocene bones by a silica-based purification method." Nucleic Acids Res. 21(16): 3913 - 3914.

Jacobsen, CS and Rasmussen, OF (1992). "Development and application of a new method to extract bacterial DNA from soil based on seperation of bacteria from soil with cation exchange resin." Appl Environ Microbiol 58(8): 2458 - 2462.

Johnston, CG and Aust, SD (1994). "Detection of Phanerochaete chrysosporium in soil by PCR and restriction enzyme analysis." Appl Environ Microbiol 60(7): 2350-4.

La Montagne, MG, Michel, FC, Holden, PA and Reddy, CA (2002). "Evaluation of extraction and purification methods for obtaining PCR-amplifiable DNA from compost for microbial community analysis." J Microbiol Meth 49: 255-264.

Lee, SY, Bollinger, J, Bezdicek, D and Ogram, A (1996). "Estimation of the abundance of an uncultured soil bacterial strain by a competitive quantitative PCR method." Appl Environ Microbiol 62(10): 3787-93.

Martin-Laurent, F, Philippot, L, Hallet, S, Chaussod, R, Germon, JC, Soulas, G and Catroux, G (2001). "DNA extraction from soils: Old bias for new microbial diversity analysis methods." Appl Environ Microbiol 67(5): 2354-9.

Moré, MI, Herrick, JB, Silva, MC, Ghiorse, WC and Madsen, EL (1994). "Quantitative cell lysis of indigenous microorganisms and rapid extraction of microbial DNA from sediment." Appl Environ Microbiol 60(5): 1572-80.

Picard, C, Ponsonnet, C, Paget, E, Nesme, X and Simonet, P (1992). "Detection and enumeration of bacteria in soil by direct DNA extraction and polymerase chain reaction." Appl Environ Microbiol 58(9): 2717-22. 
Porteous, LA, Armstrong, JL, Seidler, RJ and Watrud, LS (1994). "An effective method to extract DNA from environmental samples for polymerase chain reaction amplification and DNA fingerprint analysis." Curr Microbiol 29(5): 301-7.

Purdy KJ, Embley TM, Takii S, and Nedwell DB (1996). "Rapid extraction of DNA and rRNA from sediments by a novel hydroxyapatite spin-column method." Appl Environm Microbiol 62 (10).

Roller, C, Ludwig, W and Schleifer, KH (1992). "Gram-positive bacteria with a high DNA $\mathrm{G}+\mathrm{C}$ content are characterized by a common insertion within their $23 \mathrm{~S}$ rRNA genes." J Gen Microbiol 138(Pt 6): 1167-75.

Sambrook, J, Fritsch, EF and Maniatis, T (1989). "Molecular cloning: A laboratory manual, 2nd edition." Cold Spring Harbour Laboratory press, Cold Spring Harbour, N. Y.

Selenska, S and Klingmüller, W (1991). "DNA recovery and direct detection of tn5 sequences from soil." Lett Appl Microbiol 13: 21 - 24.

Steffan, RJ, Goksoyr, J, Bej, AK and Atlas, RM (1988). "Recovery of DNA from soils and sediments." Appl Environ Microbiol 54(12): 2908-15.

Strohl, WR (1992). "Compilation and analyis of DNA sequences associated with apparent Streptomycete promoters." Nucleic Acids Res 20: 961-974.

Tebbe, CC and Vahjen, W (1993). "Interference of humic acids and DNA extracted directly from soil in detection and transformation of recombinant DNA from bacteria and a yeast." Appl Environ Microbiol 59(8): 2657-65.

Torsvik, V, Goksoyr, J and Daae, FL (1990). "High diversity in DNA of soil bacteria." Appl Environ Microbiol 56(3): 782-7.

Tsai, YL and Olson, BH (1991). "Rapid method for direct extraction of DNA from soil and sediments." Appl Environ Microbiol 57(4): 1070-4.

Tsai, YL and Olson, BH (1992). "Rapid method for separation of bacterial DNA from humic substances in sediments for polymerase chain reaction." Appl Environ Microbiol 58(7): 2292-5.

Volossiouk, T, Robb, EJ and Nazar, RN (1995). "Direct DNA extraction for PCR-mediated assays of soil organisms." Appl Environ Microbiol 61(11): 3972-6.

von Wintzingerode, F, Gobel, UB and Stackebrandt, E (1997). "Determination of microbial diversity in environmental samples: Pitfalls of PCR-based rRNA analysis." FEMS Microbiol Rev 21(3): 213-29.

Wikstrom, P, Wiklund, A, Andersson, AC and Forsman, M (1996). "DNA recovery and PCR quantification of catechol 2,3-dioxygenase genes from different soil types." $\underline{\mathrm{J}}$ Biotechnol 52(2): 107-20. 
Zhou, J, Bruns, MA and Tiedje, JM (1996). "DNA recovery from soils of diverse composition." Appl Environ Microbiol 62(2): 316-22. 


\section{Figure legends}

FIG. 1: Comparison of different DNA isolation methods for pure cultures (A) and pure cultures with autoclaved soil (B). DNA was separated in 1\% agarose gels lanes 1, 1-kb-ladder

lanes 2, 5, Pseudomonas lanes 2 - 4: Zhou

lanes 3,6, Arthrobacter lanes 5 - 7: Moré

lanes 4, 7, Rhodococcus

A: isolation of DNA from pure cultures

B: isolation of DNA from pure cultures added to autoclaved soil

FIG. 1C: Isolation of DNA from autoclaved soil. DNA was separated in a $1 \%$ agarose gel lane1, 1-kb ladder

lane 2, DNA isolation method of Zhou

lane 3, DNA isolation method of Moré

FIG. 2: Isolation of DNA by combination of the methods of Zhou and Moré. $0.5 \mathrm{~g}$ autoclaved soil samples were spiked with different cultures (Pseudomonas, Arthrobacter and Rhodococcus). First DNA was extracted by the Zhou-method and from the remaining cells DNA was subsequently extracted by the Moré-method. DNA was separated in 1\% agarose gels

lane 1, 1-kb-ladder;

lanes 2, 5, autoclaved soil + Pseudomonas $1.8 \mathrm{ml}$

lanes 3, 6, autoclaved soil + Arthrobacter + Rhodococcus each $900 \mu 1$ 
lanes 4, 7, autoclaved soil + Arthrobacter + Rhodococcus + Pseudomonas each $600 \mu 1$ lanes 2-4: Zhou, lanes 5-7: Moré

FIG. 3: PCR-amplification of domain III of 23S-rRNA using DNA isolated from a mixture of $0.5 \mathrm{ml}$ microorganisms (Pseudomonas, Arthrobacter, Rhodococcus) from the stationary phase and $0.5 \mathrm{~g}$ autoclaved soil. DNA was separated in a $2 \%$ agarose gel lane 1, 100-bp-ladder lane 2, template DNA isolated by method of Zhou lane 3, template DNA isolated by method of Moré lane 4, template DNA Streptomyces isolated with Qiagen-Genomic DNA Kit lane 5, template DNA E. coli isolated with Qiagen-Genomic DNA Kit

FIG. 4: PCR-amplification of domain III of 23S-rRNA using DNA isolated from soil sample with addition of $200 \mu 1$ Rhodococcus cells. DNA was separated in a $2 \%$ agarose gel lane $1,1 \mathrm{~kb}$-extension ladder lane 2, template DNA isolated by method of Zhou lane 3, template DNA subsequently isolated by method of Moré lane 4, template DNA Streptomyces isolated with Qiagen-Genomic DNA Kit lane 5, template DNA E. coli isolated with Qiagen-Genomic DNA Kit 
Figures
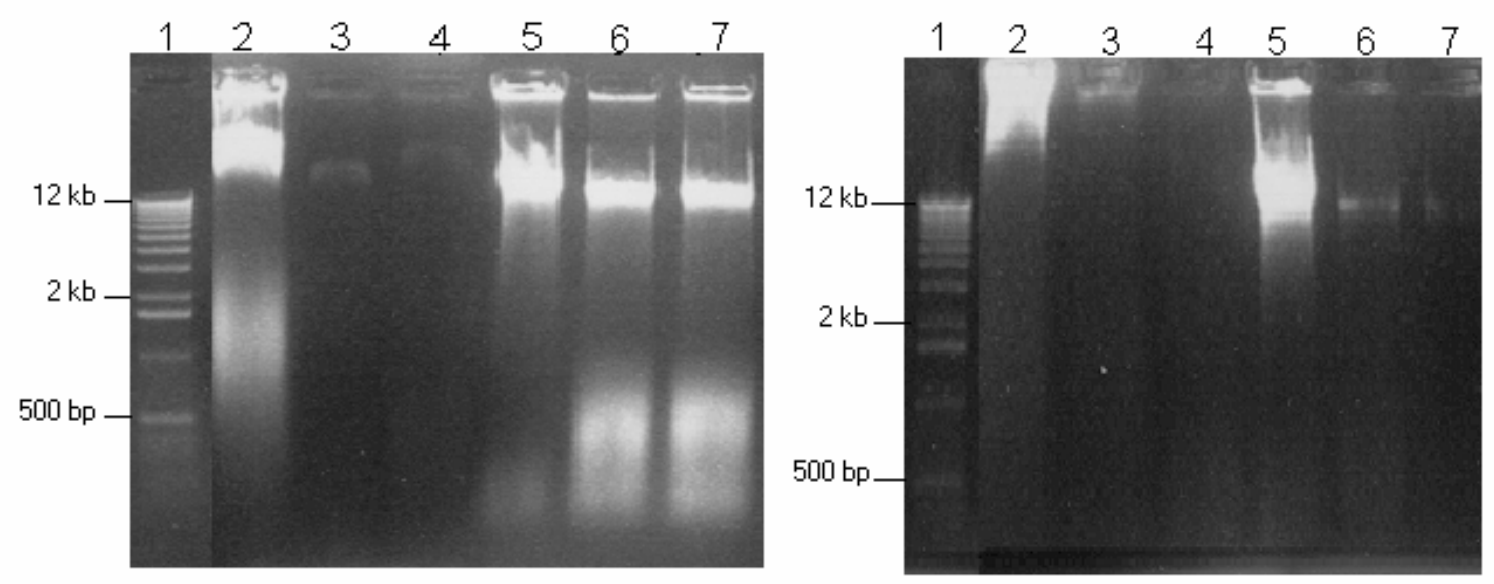

FIG. 1A

FIG. 1 B

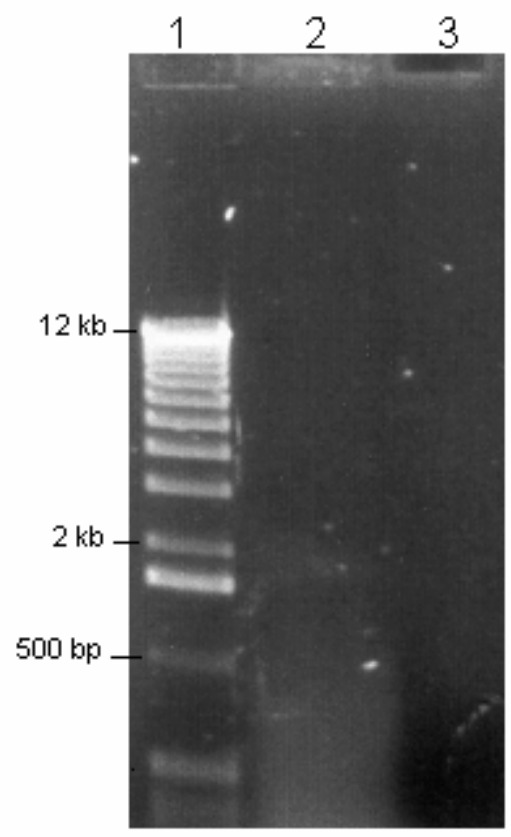

FIG. 1C 


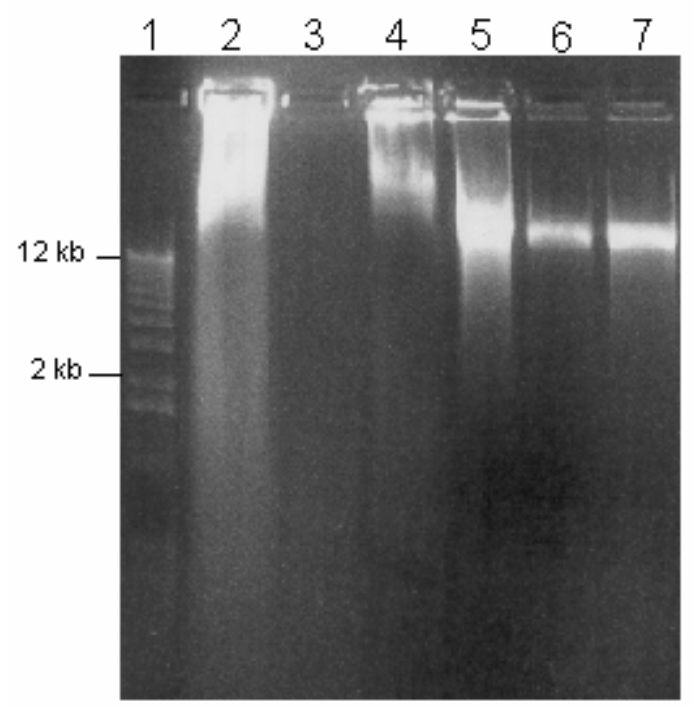

FIG. 2 


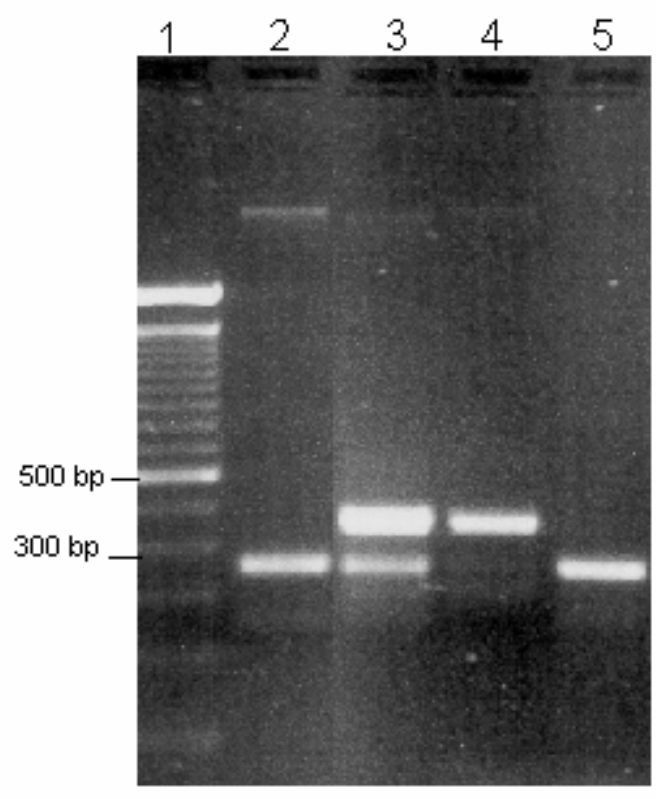

FIG. 3 


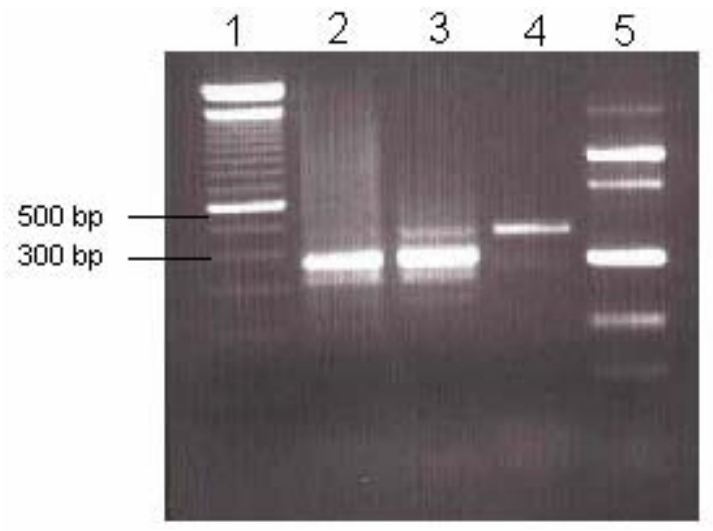

FIG. 4 